\title{
Social Representations of Earthquakes: A Study of People Living in Three Highly Seismic Areas
}

\author{
Helene Joffe, ${ }^{\text {a) }}$ Tiziana Rossetto, ${ }^{\text {b) }}$ Christian Solberg, ${ }^{\text {a) }}$ and \\ Cliodhna O'Connor ${ }^{\text {a) }}$
}

\begin{abstract}
Much research on people's seismic adjustment activity in highly seismic areas has assumed that low levels of adjustment are attributable to insufficient awareness of seismic risk. Empirical evidence for this assumption is weak, and there is growing appreciation of the role played by sociocultural and emotional variables in risk perception and behavior. This study explored these sociocultural and emotional dimensions via 144 interviews and questionnaires, with matched samples of locals in Seattle (United States), Osaka (Japan), and Izmir (Turkey). The data showed that high awareness of possible seismic adjustment measures was not translated into behavior, with all sites demonstrating low adjustment uptake, though the North Americans adopted significantly more adjustments than the other cultures. Thematic analysis of the interview data suggested that adjustment behavior was undermined by anxiety, distrust, distancing self from earthquake risk and fatalistic beliefs. The paper concludes by recommending how culture-specific disaster mitigation plans may be developed to address these factors. [DOI: 10.1193/1.4000138]
\end{abstract}

\section{INTRODUCTION}

The study reported in this paper examines lay people's representations of earthquakes in Seattle, Osaka, and Izmir. Each of these cities is located in a highly seismic area-with $10 \%$ in 50 year probability PGA values estimated between $0.4 \mathrm{~g}$ and $0.6 \mathrm{~g}$ by Giardini et al. (2003) - and has not been substantially affected by a damaging earthquake in recent decades. This level of seismic hazard and experience is representative of many other cities worldwide. The cities were chosen as research sites for investigation of the following three questions:

1. How do people living in highly seismic areas see their earthquake risk?

2. Do they prepare for a potential earthquake?

3. What is the link between how they see their risk and how they prepare for potential earthquakes?

The study aims to answer these questions using the free association interview technique (Joffe 2011), with matched samples of locals in each area. The study adopts a social

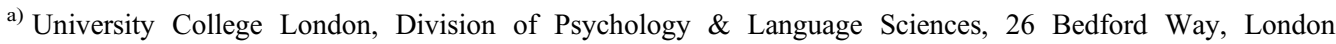
WC1H 0AP

b) University College London, Department of Civil, Environmental \& Geomatic Engineering, Chadwick Building, Gower Street, London WC1E 6BT
} 
representations approach, which strives to provide an in-depth, systematic study of commonsense thinking in relation to earthquakes, examining what form it takes and what consequences it has for people's protective behavior. The interviews are accompanied by a questionnaire that provides quantitative data on people's seismic preparedness and mitigation measures, among other factors. The understandings gleaned from this data are expected to contribute to earthquake disaster risk reduction initiatives.

This paper begins by summarizing the main findings of existing studies on the link between risk perception and seismic adjustment in earthquake-prone regions. It then states the motivation for the choice of the current study sites and provides background information on the cities. Next, it presents the approach used to explore how lay people in each of the three cities represent earthquakes. The findings of the study are presented in terms of the main themes that emerge. Finally, the paper discusses how the study answers the three research questions and its implications for disaster risk reduction.

\section{PAST PSYCHOLOGICAL STUDIES OF EARTHQUAKE-PRONE AREAS}

Much existing research on how various communities respond to and understand earthquake hazards has used psychological models of behavior, thought, and feeling. This literature has been summarized in Lindell and Perry (2001) and more recently in Lindell (2013) and Solberg et al. (2010). Predominant in this literature is quantitative evidence that people living in seismic areas often take few seismic adjustment actions. Here, seismic adjustment refers to actions and behaviors undertaken by individuals and households that have the capacity to either reduce risk of damage and loss during an earthquake, or to aid preparation for post-impact recovery (Mulilis and Lippa 1990, Solberg et al. 2010, Spittal et al. 2006, Tierney et al. 2001, Turner et al. 1986). Such adjustments range from purchasing earthquake insurance to having an emergency bag, from retrofitting one's home to ensuring that heavy objects are securely fixed. Given the evident scarcity of adjustment, the literature has concentrated on identifying the factors that predict seismic adjustment behavior (or lack thereof), with most researchers focusing on the roles played by risk perception, attitudinal factors, and behavioral intentions.

Risk perception has been one of the most frequently studied aspects of disaster risk response. There is a widespread assumption that perceiving that one lives with seismic danger on the horizon is a necessary, and perhaps sufficient, condition for seismic adjustment behavior. However, there is at best equivocal support for the proposition that risk perceptions predict adjustment behavior; heightened perception that earthquakes pose a risk does not inevitably lead to greater risk reduction efforts among households and individuals (Lindell and Perry 2000, Rossetto et al. 2011). The assumption that individual risk perception leads to reduction efforts is faulty for a number of reasons, principally that human action is not driven solely by conscious, rational decision-making carried out by individuals (Joffe 2003, Joffe and O'Connor 2013). Rather, emotional and sociocultural factors play a key role in people's risk-related behavior. There is growing recognition of the importance of these factors, with the risk perception field shifting from an almost exclusive focus on consciously available cognitions to appreciation of the role played by sociocultural and emotional factors in driving behavior (Slovic 2010). Some such factors that have emerged regarding earthquake adjustment are elaborated below. 
One social-emotive variable that has been implicated in seismic adjustment is societal trust. Levels of trust in the competence and moral integrity of political, civic, voluntary, scientific, and industrial actors in emergency management have been shown to influence seismic adjustment behavior. Trust in the competence of expert agencies and political elites promotes uptake of adjustments (Paton et al. 2010), while active distrust of those involvedfor example, due to perceptions of corruption - undermines it (Green 2008). Thus, the level of trust people have in such agents and institutions shapes their orientations toward engaging in adjustment behavior.

Seismic adjustment is also shaped by attributions of responsibility for disaster protection. Ascriptions of responsibility influence who takes what protective actions, with attribution of responsibility to self or household encouraging adjustment behaviors, and attribution to the state and other institutions discouraging it. Rather than a judgment made independently by individuals, attribution of responsibility appears to be an intrinsically cultural phenomenon, shared within a community and varying across time and place. Results from U.S. studies (Jackson 1981, Turner et al. 1986, Arlikatti et al. 2007) indicate a shift over time in the public's ascriptions of responsibility for earthquake protection, from the state to the household level. In contrast, the Japanese cultural and political emphasis on collectivism and state action is reflected in greater responsibility attributed to the state on the part of Japanese people (Palm and Carroll 1998). These Japanese attributions correlate with lower seismic adjustment activity relative to their U.S. counterparts, suggesting that cultural processes that direct responsibility toward agents other than self may undermine individuals' seismic adjustment motivation.

A further cluster of factors shaping seismic adjustment relates to control. Social and psychological research has established that a prerequisite for risk-reducing behavior is that people must believe that their actions will be effective in controlling the risk (Bandura 1977). Thus, performance of seismic adjustment behaviors depends on individuals' and households' confidence in the efficacy of their behavior in controlling the threat. Important in determining such perceived efficacy are people's relevant knowledge, skills, and resources. For example, understanding why one type of building survived an earthquake intact while another collapsed helps people to see that building design is a major cause of loss, allowing them to infer more easily that losses are controllable (McClure et al. 2001, McClure et al. 2007). However, efficacy is not purely a knowledge-driven and individual-level construct. People resolve issues of risk and uncertainty in negotiation with other people. People turn to similar others - such as family, neighbors, and political leaders with whom they identifyfor information on how to think and behave. People may then adapt their behavior to conform to (or mimic) the norm in their reference group. This was shown in a study by Mileti and Fitzpatrick (1992), wherein people's seismic adjustments increased when they observed other people undertaking such actions. Arising from such processes is a sense of collective efficacy relating to a risk, that is, the confidence a group or community has in their collective ability to identify risks and implement adjustments. High collective efficacy has a positive influence on seismic adjustment (Paton et al. 2010), as do strong and durable community ties (Turner et al. 1986).

Collective efficacy is situated within a network of other cultural beliefs that can either enhance or undermine adjustment behavior. Particularly important in this regard is fatalism, 
which research has found to be pervasive in the earthquake-related orientations of many cultures and subcultures (McClure et al. 2001). Fatalism stems from a cultural emphasis on the insurmountable power of the natural, religious, or human forces that are variously seen as responsible for earthquakes' consequences. Faced with these forces, individuals or communities may feel that they cannot protect themselves from disasters. Fatalistic attitudes are significant obstacles to high efficacy beliefs, and thereby to motivation to protect oneself from risk.

The sociocultural approach to people's orientations to earthquake risk, which encompasses the variables outlined above, offers rich potential for exploring the three research questions introduced at the start of this paper. However, the existing literature has important shortcomings. Firstly, very few studies (the exception being Palm and Carroll's [1998] U.S.Japanese research) have attempted to provide a systematic documentation of cultural variability in earthquake orientations. Most research has concentrated on studies of single cultures, predominantly the United States and New Zealand. Cross-cultural work has the potential to demonstrate unambiguously the role played by sociocultural forces in seismic risk representation and adjustment. Secondly, most of the research reviewed above is based on quantitative data gleaned from surveys (questionnaires) that provide participants with limited response options. In developing a questionnaire, the researcher usually predefines the range of responses participants can choose. Given this format, it is difficult for "new" types of responses that have not been anticipated by the researcher to emerge. Furthermore, the more complex, contradictory motivations of human action are not readily revealed through questionnaire-based studies. Thus, while questionnaire studies are useful for providing self-report information on what measures people take to protect themselves from earthquakes (Question 2), they give limited insight into the link between how people see their risk and the protective actions they take (Questions 1 and 3).

A different approach is needed in order to examine the key, perhaps as yet undiscovered, drivers of seismic adjustments across a range of cultures. A fitting framework is social psychology's social representations theory (Moscovici 2008), which guides this study. Social representations are networks of concepts, images, and feelings that are shared between members of a community (Moscovici 1988). While they manifest in what individuals say about a given topic, they are underpinned by sociocultural, historical, and group-specific ideologies. The social representations that define how a culture sees a phenomenon are best tapped by way of techniques that allow participants to associate freely on a topic such as "earthquakes" (Joffe 2011). The associations that they spontaneously generate reveal their naturalistic pathways of thought. These chains of association are not only more likely to uncover the underlying drivers of their actions, but are also more emotive in content than data arising from survey methods (Hollway and Jefferson 1997). By exploring these associations via depth interviews, one is able to identify the constituent elements of cultural representations of earthquakes.

\section{SITE SELECTION AND CONTEXT}

Three sites were chosen for this study: Seattle (United States), Osaka (Japan), and Izmir (Turkey). These were selected as they are located in areas of high seismic hazard and, as such, are vulnerable to future earthquake disasters, but at the time of the research had not been 
directly affected by damaging earthquakes. Such populations are assumed to be in the predisaster (i.e., the "mitigation" or "preparedness") phase of the disaster management cycle (Wisner and Adams 2002). They are also all coastal cities, with developed port and transport infrastructures, and have the potential to be affected by tsunami.

Finally, the cities are representative of three distinct cultures. While all three countries are secular democracies with capitalist economies and, as such, are broadly similar in political structure and legal institutions, culturally they belong to different spheres. The United States is primarily a Christian nation and is widely regarded as a culture that prizes individualism, self-reliance, meritocracy, and entrepreneurialism (Brewer and Chen 2007). The Japanese belong, in the main, to the national Shinto religion, as well as Buddhism, and their culture is widely seen as a counterpoint to Western individualism, with the group and the nation prioritized over the individual (Brewer and Chen 2007; though see Gjerde and Onishi 2000 for a dissenting view). Turkey is a primarily Muslim country and is largely collectivist and hierarchical (Hofstede 1983).

\section{SEATTLE}

Seattle lies on the Pacific coast of the United States, along the Puget Sound. With a population of over two million people in the greater urban area, it is the largest city on the northwest coast of the United States. It is a major seaport and the economic, political, and cultural center of the region. Geologically the Seattle area is home to a number of faults belonging to the regional Puget Sound fault zone (Blakely et al. 2002, Johnson et al. 1999), and the greater Seattle area has experienced at least 12 earthquakes of magnitude 5 or more since the start of the twentieth century. In particular, buildings in Seattle were damaged in an earthquake (M5.7) on 14 February 1946 (USGS 2009); West Seattle sustained major damage (up to Intensity VIII) in a M6.5 earthquake on 29 April 1965 (USGS 2009); and some areas of South Seattle were damaged in the M6.8 28 February 2001 Nisqually earthquake (EERI 2001). In the latter case, damage occurred primarily in old reinforced masonry structures and older-design bridges, and was spatially limited. The Cascadia subduction zone, separating the Juan de Fuca and the North American plates, also lies offshore of Seattle. Historic activity on this subduction fault has generated large earthquakes with attendant tsunami. The last such event is believed to have occurred in 1700 (Yamaguchi et al. 1997).

\section{OSAKA}

Osaka lies on the southern end of Japan's main island Honsh , on the shore of Osaka Bay. With a population of more than 2.5 million people it is the third most populous city in Japan and is generally regarded as the most important city after Tokyo, in terms of economy, culture, and politics. Together with Kobe and Kyoto, it forms the Keihanshin area, with a total population of over 18 million people, making it one of the most densely populated and prosperous regions in the world. This area is home to extensive fault systems such as the ArimaTakatsuki tectonic line and the Median tectonic line (Kanaori and Kawakami 1996). In addition, several faults run underneath the city itself, such as the Ueamachi fault and the Ikoma fault (Irikura 2000). The last major seismic event in this area was the 17 January 1995 M6.8 Hanshin (Kobe) earthquake. This killed more than 6,400 people, mainly in the area between the cities of Kobe and Nishinomiya and caused more than $\$ 100$ billion in losses 
(EEFIT 1997). Osaka itself suffered very little direct damage. Osaka was not affected by the 11 March 2011 Tōhoku-oki earthquake and tsunami that devastated northern Japan, and the current research preceded this event.

\section{IZMIR}

Izmir is situated in the Gulf of Izmir on the western shore of Anatolia, Turkey, on the coast of the Aegean Sea. With a metropolitan population of more than three million people, it is the third most populous city in Turkey after Istanbul and Ankara. While in earlier times an important seaport, today it is a major industrial center. Izmir is located at the west part of the Gediz Graben system and in the vicinity of the active Karaburun, Tuzla, Kemalpaşa and Izmir faults (Akinci et al. 2000). The city has historically been affected by several large earthquake events. Of note are the two earthquakes and tsunami that hit the region in 1688, killing approximately 31,000 people (NOAA 2011). Another major earthquake (estimated M7.3) struck in 1883, killing some 15,000 people in the region. The city was spared major disasters in the twentieth century, with only four earthquakes above M5 occurring and three earthquake-related deaths (NOAA 2011).

\section{PARTICIPANT SAMPLING AND INTERVIEW METHODOLOGY}

\section{SAMPLING OF PARTICIPANTS}

Professional research recruitment companies were contracted to enlist matched samples of 48 participants in each of the three locations $(N=144)$. All samples contained eight participants in each of the age groups 20-29, 30-39, 40-49, 50-59, 60-69, and 70-79, with each age group split evenly in terms of gender and socioeconomic status (with half above and half below the median household income for that location). All participants had lived in the area for the majority of their lifetimes and were native-born citizens of their countries.

\section{COLLECTION OF INTERVIEW AND QUESTIONNAIRE DATA}

All of the interviews were conducted by native-level speakers of the local language. The three interviewers underwent training to ensure uniformity in the way the interviews were conducted. Following a pilot phase, the data were gathered in the course of semi-structured, in-depth, digitally recorded interviews. The interviews took place between late 2008 and early 2009 in facilities provided by the recruitment companies.

Participants were blind to the specific focus of the study, having simply been informed that the interviews would be about environmental issues. Initially participants were provided with a risk ranking task, which asked them to select five hazards from a range of 20 humanmade, natural, health, and societal hazards and rank these according to how personally threatening they thought they were. Following this, participants were presented with a grid of four empty boxes on a piece of paper, in accordance with Joffe's (2011) free association interview technique. They were prompted to write or draw in each box any image or word that came to mind when they heard the term "earthquake." Figure 1 displays an example grid. Subsequently respondents were asked to talk about what they had inscribed in each box. The aim was to elicit naturalistic and subjectively relevant material. Thus use of prespecified interview questions was avoided, though a small set of prompt questions was used for 


\section{INSTRUCTIONS:}

We are interested in what you associate with earthquakes. Please express what you associate by way of images and/or words. Please elaborate one imageiword per box. Sometimes a really simple drawing or word can be a good way of portraying your thoughts and feeings.

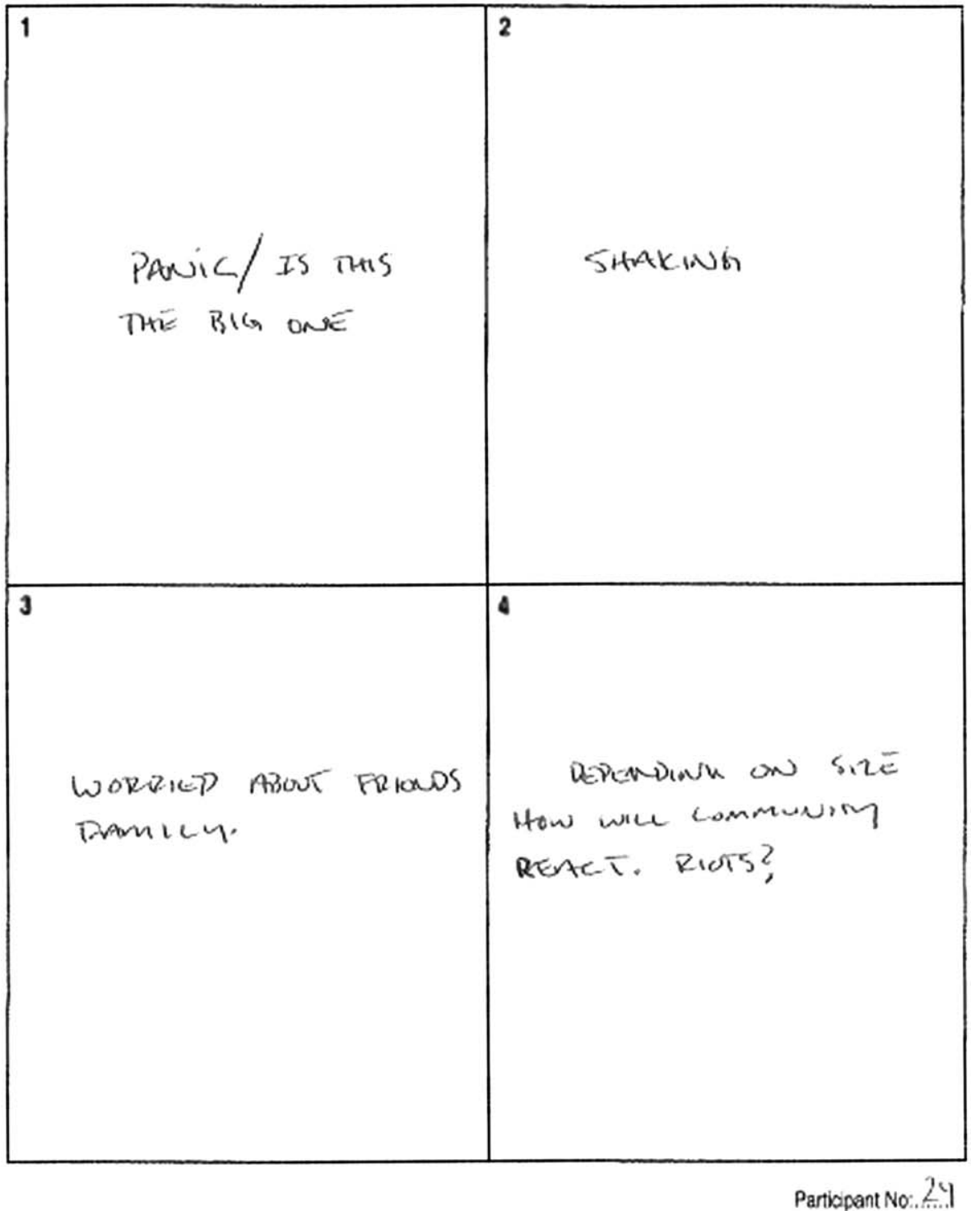

Figure 1. Example of free-association grid (completed by 40-year-old American male). 
participants who volunteered little spontaneous elaboration of their grid content. All interviews were audio-recorded and subsequently transcribed, and the Japanese and Turkish interviews were translated into English. The data were then imported into the ATLAS.ti qualitative data analysis software package (ATLAS.ti 2011) for analysis.

At the end of the interview, respondents were asked to fill out a questionnaire that ascertained demographic data, residence characteristics, perceived seismic vulnerability of their home, and seismic mitigation and preparedness measures undertaken.

\section{DATA ANALYSIS}

Two types of data were obtained: the questionnaire and initial risk ranking task (quantitative) and the interview dialogue (qualitative).

The quantitative data gathered from the questionnaires and risk rankings were entered into SPSS (IBM SPSS 2011) and subjected to statistical analysis.

The qualitative data underwent a thematic analysis, an analytic technique for identifying the most prevalent patterns of meaning in a dataset (Boyatzis 1998). Such patterns are those that are most important in characterizing the phenomenon under study. The full process whereby such an analysis is conducted is described in Joffe (2011). Interview transcripts were coded or categorized according to a coding frame devised by the researchers to reflect the content of the interviews (this can be obtained from the authors). During its development, the coding frame was applied to a randomly chosen sample of $25 \%(n=36)$ of the interviews by two independent coders. The outcomes of these two analyses were compared to evaluate the precision and scope of the coding frame. The coding frame was refined on this basis. The computer package ATLAS.ti was used to code transcripts, with data segments that corresponded to a particular code electronically tagged as such.

Since the aim of qualitative analysis is to provide a depiction of the content of people's interviews, formal statistical analysis of the coded data is not appropriate. This said, it is important that the content that is discussed is prevalent throughout the data corpus, rather than present in only small numbers of interviews. The thematic analysis was therefore guided by an initial generation of a frequency table that identified which codes were most prevalent, that is, the proportion of interviews in which they appeared. Those found in over half of the interviews in at least one of the sites were deemed most important and interlinked codes (sometimes with lower prevalence) were grouped with them to form the key themes.

\section{RESULTS}

\section{RESULTS OF THE QUESTIONNAIRE-BASED ANALYSIS}

\section{Risk Rankings}

Table 1 shows the five hazards rated most threatening by participants in each country. Earthquakes appeared in the top five for all three countries and are the only natural hazard to appear in the table. The results of this risk-ranking show that in all three sites earthquakes were seen as a major threat. Although all three sites are also at risk of potential tsunami, this hazard was not perceived to be a large threat; it ranked the least threatening of all 20 hazards 
Table 1. The five most threatening hazards per country

\begin{tabular}{llll}
\hline \hline Rank & United States & Turkey & Japan \\
\hline 1 & Economy & Terror & Earthquakes \\
2 & Cancer & War & Nuclear \\
3 & Crime & Earthquakes & Terror \\
4 & Terror & Nuclear & War \\
5 & Earthquakes & Cancer & Crime \\
\hline \hline
\end{tabular}

in Turkey and the United States and the fifth least threatening hazard in Japan. It should be noted that this study precedes the 2011 Tohoku-oki, Japan, earthquake and tsunami.

\section{Seismic Adjustment Behavior}

Using an adaptation of Spittal et al.'s (2006) preparedness measures scale, participants were asked to indicate which of 19 mitigative and preparatory seismic adjustments they had adopted. The seismic adjustment measures and their rates of uptake are shown in Figure 2. U.S. participants had adopted an average of 9.19 adjustments, with the Japanese averaging 6.83 and the Turkish 5.25 (Table 2). A one-way, between-groups ANOVA detected a significant difference between these means, $F(2,141)=13.82, p<.001$. Post-hoc tests revealed that the U.S. mean level of adjustment was significantly higher than that of both Japan and Turkey, while the difference between Japan and Turkey was not statistically significant. In Figure 2, it is clear that the preferred types of seismic adjustment were generally of a "preparatory" type, that is, measures that would increase survival chances after an event-such as storing

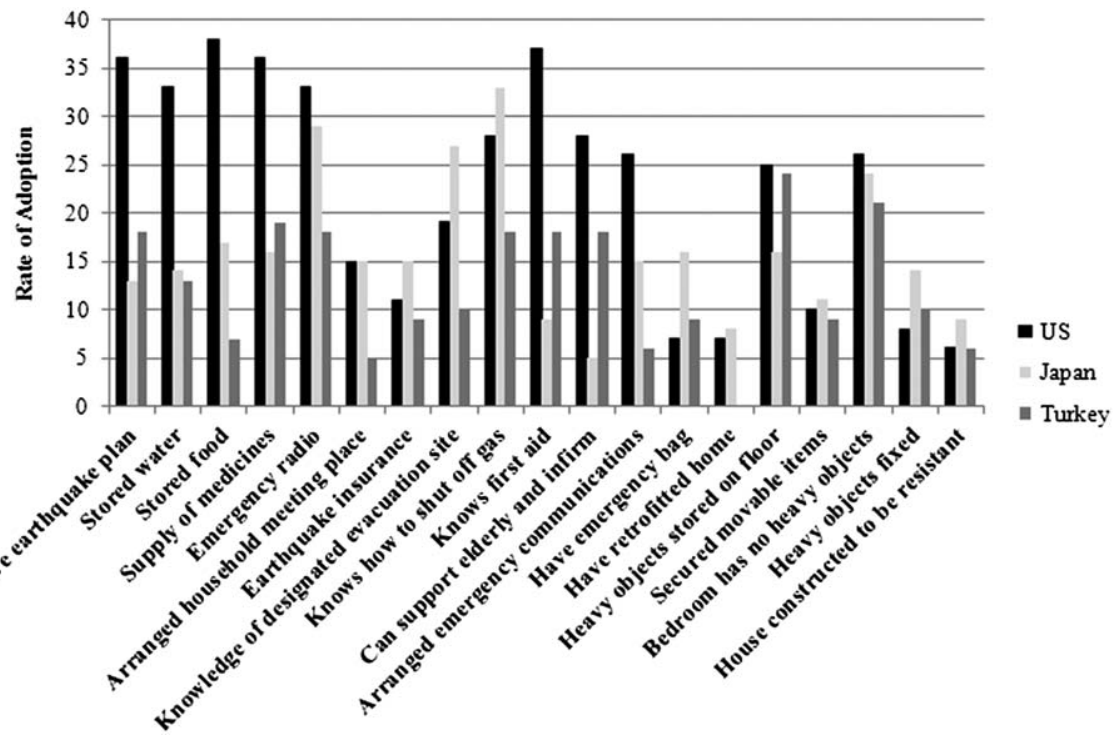

Figure 2. Number of people in each site who had adopted each adjustment measure. 
Table 2. Mean number and standard deviation of adjustments adopted in each country

\begin{tabular}{lcc}
\hline \hline Country & Mean & Standard Deviation \\
\hline United States & 9.19 & 4.11 \\
Japan & 6.83 & 3.25 \\
Turkey & 5.25 & 3.66 \\
\hline \hline
\end{tabular}

food, water, and medicines and familiarization with designated evacuation sites and how to shut off one's gas supply. These are measures that are simple, low-cost, and relevant to multiple hazards (not just earthquakes). Structural retrofitting was especially rare, undertaken by no Turkish and only eight Japanese and seven American participants. Statistical analysis found no significant difference in levels of adjustment uptake between those below and above the respective location's median income, $t(142)=.48, p>.05$.

\section{Residence Characteristics}

Table 3 displays the characteristics of participants' residences, containing information on average age of houses, median number of floors, the proportion of participants who owned or rented their property, the proportion of residences that were houses or apartments, and the primary materials used in the construction of their buildings. Referring to the evolution of seismic building codes in each country, the reported age of the vast majority of structures in all three countries would place them as pre-seismic code or old code (i.e., inadequate applied lateral load according to current seismic hazard assessments and lack of capacity design), hence potentially vulnerable to earthquake damage. The majority of buildings are also low- to medium-rise and are predominantly of concrete construction in the Turkish and Japanese samples, and wooden in the U.S. sample. Except for Japan, where a greater proportion of wooden houses might have been expected, the building classes present in the samples are reasonable representations of the proportion of different housing types in the three cities.

Table 3 shows clear cross-national differences in the types of properties in which people lived. Most Seattle residents lived in houses and most Izmir residents in apartments, with the Osaka sample split approximately evenly between house- and apartment-dwellers. Further, most Japanese and U.S. participants owned their properties, while almost half of the Turkish sample rented their homes. Analysis revealed statistical links between these factors and adjustment behavior. In the sample as a whole, type of residence (i.e., house/apartment/other) showed a statistically significant relationship with adjustment behavior $(F[2,141]=9.82, p<.001)$, with post-hoc tests revealing that residents of houses adopted significantly more adjustments (mean $=8.64$, standard deviation $=4.33$ ) than apartment-dwellers (mean $=5.78$, standard deviation $=3.23$ ). Adjustment behavior was also significantly linked with conditions of occupancy of the residence $(F[2,141]=4.01, p<.05)$, with those who owned their home performing more adjustments (mean $=7.72$, standard deviation $=4.25$ ) than those who lived in rented properties $($ mean $=5.67$, standard deviation $=3.37$ ). The influence of residence characteristics was most visible for adjustments relating to structural features of one's home, such as engaging in retrofitting practices (all those who reported retrofitting owned their home and all but two lived in houses) and knowledge of how to turn off the gas supply. 


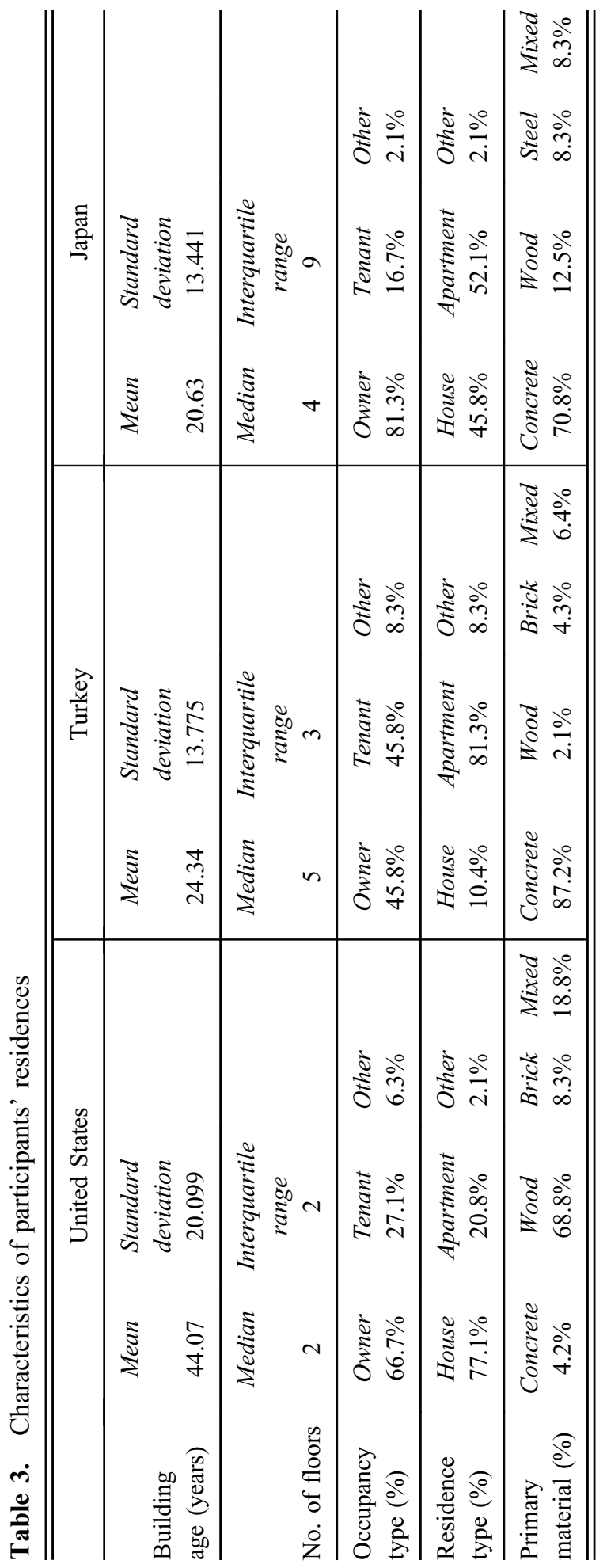


Table 4. Perceived vulnerability of residence

\begin{tabular}{lc}
\hline \hline Country & Mean Likert scale response \\
\hline United States & 2.61 \\
Japan & 2.12 \\
Turkey & 2.15 \\
\hline \hline
\end{tabular}

\section{Perceived Risk}

The survey included a question designed to assess perceived vulnerability of the structures in which people lived. Participants were asked, "How safe would you feel inside your house if an earthquake occurred?" with responses provided on a Likert scale ranging from 1 (not safe) to 4 (completely safe). Table 4 summarizes the mean responses for this item. A significant difference was detected between the three countries in levels of perceived safety, $F(2,126)=4.22, p<.05$. Post-hoc tests revealed that the Americans reported feeling significantly safer than either the Japanese or Turkish. Japanese and Turkish scores were not significantly different from each other.

As well as country, residence type and conditions of occupancy also showed a relation with perceived safety inside one's home. Owners reported feeling significantly safer in their home than renters $(F[2,126]=3.42, p<.05)$ and those living in houses felt significantly safer than those in other types of residence $(F[2,126]=5.32, p<.01)$.

Statistical analysis of the data as a whole showed that perceived safety was significantly positively correlated with number of adjustments adopted $(r[127]=.23, p<.01)$; that is, feeling safer was linked to performing more adjustments.

\section{Discussion of Questionnaire Results}

These results suggest that those who performed most adjustment behaviors were those who felt most secure about their safety during earthquakes, and vice versa. The U.S. participants, who felt significantly safer in their home than the Turkish or Japanese participants, performed significantly more adjustment behaviors. Likewise, property owners and housedwellers felt safer in their homes and were more likely to undertake adjustment activities. The causal nature of the relationship between perceived safety and adjustment uptake is difficult to ascertain. It is possible that Seattle residents, property owners, and house-dwellers felt safer precisely because they had already taken actions to reduce their risk. Alternatively, it is possible that high levels of perceived vulnerability may actually have inhibited Osaka and Izmir residents, tenants, and apartment-dwellers from taking action. The latter would contradict the usual assumption of the risk perception literature that the more at risk people feel, the more likely they are to take action to reduce the risk.

Adjustment behavior fluctuated across two dimensions: country and residence characteristics. It is difficult to disentangle which has the more decisive influence on levels of adjustment, as the two dimensions are heavily interlinked, with typical residence characteristics varying systematically across cultures. Residence patterns and cultural context are not 
independent factors; rather, typical residence characteristics are an aspect of cultural context, with the typical residence patterns that evolve reflecting a culture's social, economic, and symbolic systems. Potentially, there are material reasons why owning one's residence and living in a house may support adjustment behavior. For example, renters may not be permitted to make substantive structural changes to their residence, and people living in apartment blocks may have little jurisdiction over the structure as a whole or over communal areas such as hallways. However, such explanations are not entirely satisfying. Figure 2 shows that the most popular adjustment behaviors (and the ones that most discriminated the U.S. participants from the Turkish and Japanese) related to preparatory behaviors like having an earthquake plan, learning first aid, and storing supplies of food, water, or medicines. It seems unlikely that material factors relating to residence characteristics would affect people's ability to undertake such measures. With analysis indicating that economic resources have no significant effect on adjustment uptake, it seems that other, non-material forces must intervene to generate differential levels of uptake of such behaviors.

The key finding from the questionnaire data is that levels of uptake of seismic adjustment measures were, overall, low. This is consistent with findings from other studies (e.g., Kirschenbaum 2005, Palm 1998, Spittal et al. 2008). Even the most enthusiastic adopters of adjustments, the U.S. participants, performed on average less than half of the suggested measures. Of particular concern, the data collected in all three sites suggest that participants' homes were built prior to modern seismic code implementation, yet only $10 \%$ of the sample had undertaken structural retrofit measures (undertaking retrofit measures was not statistically related to income). The low uptake of adjustment among people who know that they are at risk of earthquakes (as the risk-ranking task showed) remains unexplained by the quantitative data. The following section describes the results of the qualitative analysis designed to interrogate the emotional and sociocultural factors that may mediate how people see their risk and the behaviors that they undertake.

\section{RESULTS OF THE INTERVIEW-BASED ANALYSIS}

Thematic analysis of the interview data revealed three major themes in the characterization of earthquakes in the three cultures. The most widespread, unanimous theme revolved around the loss and destruction wrought by earthquakes. This theme, indicating that people think of loss of life and home in relation to earthquakes, is not examined in detail in this paper. Instead, attention is focused on the second and third most prevalent themes, which throw most light on the research questions: emotional and moral responses to earthquakes and agency and control regarding earthquakes. Within each culture, representations were relatively consensual, with high levels of commonality across factors like gender, age and income. The few areas where demographically relevant differences emerged are indicated within the below text.

\section{Theme 1: Emotional and Moral Responses to Earthquakes}

Figure 3, which displays the number of interviews in which each code appeared in each country, shows that participants at the three sites exhibited strong and distinct emotional and moral responses to earthquakes. Overall, fear and anxiety-related emotions were the most prevalent in all three countries, with Turkish participants showing an especially 


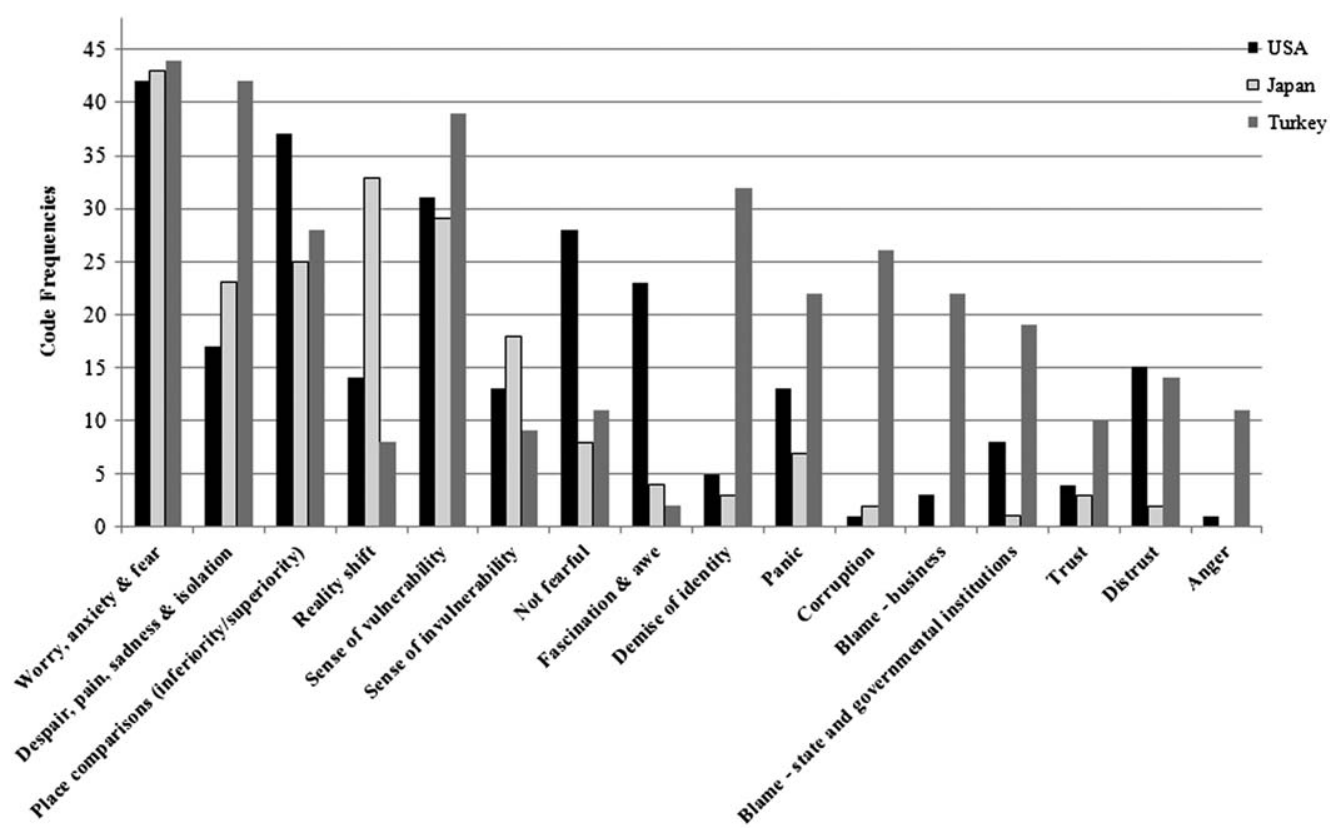

Figure 3. Frequency of emotional and moral codes by country.

large fear response. Turkish participants also showed greater prevalence of grief- and traumarelated emotions and displayed considerably more emotions relating to moral issues such as corruption (e.g., anger, distrust, blame). U.S. participants had a greater tendency than the other two cultures to say that they were not fearful of earthquakes and were also striking in the frequency with which they mentioned feelings of fascination and awe in relation to earthquakes. The Japanese stood out for the prevalence of the "reality shift" code in their interviews, which refers to narratives that indicate that their beliefs about their vulnerability to earthquakes underwent a radical re-orientation following their experience of the 1995 Kobe earthquake. However, the Japanese sense of invulnerability was also marked, twice as prominent as in the Turkish data. In the following sections, these similarities and differences are examined in greater depth.

\section{U.S. Responses}

The quantitative data furnished a picture of the U.S. participants as those who lived in their own houses, did relatively more to prepare for earthquakes and felt less at risk from earthquakes than did the Turkish and Japanese respondents. The qualitative data threw further light on the psychology of the U.S. sample. The dominant emotional association with earthquakes for U.S. interviewees was one of worry, anxiety, and fear. This was expressed both with regard to past events and future earthquakes:

"Certainly there would be intense fear, I mean, you know, you have no sense of safety because you wouldn't know: Would it be safer to go out or do you stay where you are?" (United States, female, 72) 
Fear of earthquakes was linked to a general sense of danger arising from damage to the built environment and consequent threats to the health and life of self and others:

"My last experience with an earthquake, I, one of the reasons I stayed in my bedroom was that I was afraid that if I went out, there would be damaged infrastructure with the roads, pipelines, water mains, things like that; there would be power lines down, that was very frightening to me." (United States, female, 66)

The fear associated with earthquakes appeared to be adulterated by awe for many U.S. participants. Approximately half related that they had experienced feelings of awe, fascination, and exhilaration during and after earthquakes, with some comparing it to being on a rollercoaster:

"I'm just in awe with, you know, with Mother Earth and, and its environment and how, you know, when, when you, maybe it's after the after effect, you know, where you're kind of thinking, 'Wow,' you know, 'that was really amazing, ' you know, because it just really shows how small you are on this planet. That at any time, you know, if Mother Earth, you know, if the Earth really wanted to take you down, I mean it can in a second. And so that's kind of the amazement and the surrealness of everything." (United States, male, 40)

Furthermore, half of the U.S. respondents who mentioned anxiety or fear in relation to earthquakes asserted at another point in their interview that they were not particularly afraid of earthquakes. This may be because they felt they could control their risk by the choices they made, such as avoiding bridges or areas where buildings are vulnerable. The assertion that they were not fearful was also tied to an acceptance and normalization of the risk:

"So there, I mean it, it's, we all live in places where there's different kinds of risk, and I think the only way you can survive is to say, 'Okay, it's not going to happen to me, ' you know, in my lifetime or this point in time, because you really can't live under that kind of fear all the time; life isn't much fun now either!" (United States, male, 61)

The disavowal of fear may have been further promoted by the tendency of a large majority of U.S. participants to anchor earthquakes in places that are geographically removed from Seattle and themselves, thereby distancing earthquake risk from self and home. Earthquakes were seen by many as a problem that was worse in other places, such as California and Asian countries. When Seattle was compared to these, the evaluation was often that Seattle is safer than other areas:

"I don't feel so threatened by it. I, I mean, I don't live on the San Andreas fault; I live in Seattle! You know, I don't live on a flood plain." (United States, female, 45)

However, negation of risk was not absolute, and earthquakes outside of the Seattle region were occasionally held up as examples of what the Seattle area might face if it too were struck by a major earthquake.

Distrust of fellow citizens and the government appeared in over a quarter of the US interviews. Distrust was related firstly to the lack of competence attributed to government and regulatory institutions, and secondly to anticipation of a societal breakdown in the event of an earthquake disaster. For some U.S. participants, the aftermath of Hurricane Katrina served as a template for what might happen in the event of a major disaster. The lesson of Katrina was 
that a disaster destroys not only the built environment, but also, according to many U.S. respondents, disrupts social cohesion and unleashes people's animalistic sides:

"I was going to use the word chaos. And it doesn't have to be focused where it's specific people, group against another specific group; it could be just craziness, people just shooting because they've got guns and ammo, you know. I mean people can be crazy, it doesn't take too much to set us off." (United States, male, 26).

In sum, in U.S. participants' emotive response to earthquakes, anxiety was often mitigated by expressions of fascination, as well as extensive disavowal of fear and personal vulnerability. Distrust of government and fellow citizens was also a feature of the emotive response to earthquakes, which were seen to have the potential to unleash social chaos.

\section{Japanese Responses}

Similarly to the U.S. data, the dominant emotional component of Japanese associations with earthquakes related to concern, worry, anxiety, and fear, with nearly all Japanese participants expressing such emotions. Fear-related emotions were tied to past earthquake experiences (with memories of the 1995 Kobe earthquake particularly prominent) and anxiety about future earthquakes. The main object of fear was concern for one's own and others' well-being in the event of collapsing objects and structures. This fear was compounded by the force of shaking, the noises produced by the earthquake, and the pervasive sense of having everyday reality violently re-arranged into an unfamiliar and threatening form:

"if I crouch down on a place that is firm, I can depend on my feeling or else there is nothing else that I can rely on. There is nothing that we can rely on in the earthquake, because it shakes where you are standing. That is why it is very scary." (Japan, male, 46)

Aside from fatalities and built environment damage, a number of objects and events were associated with fear, including loss of goods and services and difficulties in contacting family and friends. In particular, the threat of fire compounded anxieties about entrapment, with the rapid onset of post-earthquake fire represented as making escape or rescue much more difficult. Not all of these responses drew on personal experience, but rather were reactions to images carried by television broadcasts and newspapers, especially during the 1995 Kobe earthquake:

\footnotetext{
"It was very scary when I watched it on TV, despite my place was okay. Everything was burning, and children were buried under and were calling for their mother. I picture this immediately." (Japan, female, 66)
}

A further characteristic of earthquakes that created fear is that they are sudden and unpredictable:

"I realized that earthquakes are very terrifying, because the great Hanshin earthquake occurred suddenly, without any warning signs." (Japan, male, 60)

The majority of Japanese participants expressed a sense that their past experience of an earthquake or similar disaster had prompted a 'reality shift,' in which their views on earthquakes were radically re-oriented. Respondents described shifting from a lack of concern to a realization that earthquakes represent a hazard that could touch Osaka and themselves:

"It made me realize that this is not some other person's concern. It was my concern too." (Japan, male, 59) 
The geographical and social ties between Osaka and Kobe made possible a personalization of earthquake risk in the minds of many respondents. If such a disaster could happen in Kobe, why not in Osaka? However, a countervailing discourse was also found in the interviews where earthquakes and other hazards were seen as distant from Osaka and more prevalent elsewhere. This distancing was achieved by contrasting Osaka with other Japanese areas thought to be at greater risk, as well as with other Asian countries, such as China and Indonesia. This strategy may have supported the noticeable tendency in the Japanese participants to state that they were not personally vulnerable to an earthquake disaster:

"I'm sorry, this may not be a nice way to describe, but in a well-developed place there are not many dead people, but like Southeast Asia and less-developed countries, people there are quite defenseless against the disaster." (Japan, male, 54)

Mentions of trust or distrust were largely absent from Japanese representations of earthquakes. Though a small number of participants alluded to poor construction practices as a source of vulnerability and as such could be seen to express some concern over the competence and integrity of the construction industry and its regulators, there were few signs of any overt distrust-related representations. Likewise, no overt feelings of anger or blame could be detected.

In summary, Japanese participants' emotional and moral reactions to earthquakes were focused on fear-related emotions, as well as emotional reactions to loss. The Kobe earthquake influenced the formation of such responses, as participants reported a sense of reality shifting, with the Kobe disaster highlighting Osaka's own earthquake risk. However, a strong tendency to maintain a sense of geographical and emotional distance from the risk also prevailed.

\section{Turkish Responses}

Compared to the U.S. and Japanese participants, the Turkish participants related earthquake stories that were invested with particularly strong and varied emotions. The Turkish sample was unique in the prevalence of their talk of corruption, blame, anger, and "demise of identity."

Nearly all Turkish participants expressed feeling a strong sense of worry, anxiety, or fear regarding earthquakes. Almost half related stories of panic, which was triple the number of Japanese mentions of panic and nearly double that of the U.S. participants:

"Especially at the moment when it happens, one is struck with panic; you hear they jump out of the window, jumped out of the balcony. You never know what one will do with that panic." (Turkey, male, 45)

Experiences with disastrous earthquakes in Turkey had created a strong emotional response connected to feelings of grief, pain, and despair. These were associated, first and foremost, with fatalities and losses to the built environment, whether past or potential:

\footnotetext{
"We get upset as humans. I mean, one gets upset. We see, we watch. One comes up on TV and says, 'My house collapsed in the earthquake, all my money is gone, my workplace is gone, my children died, my spouse died.' We haven't lived that, but assuming that we might live it one day, and if one has a little feeling of consciousness and mercy, one gets upset. You can't ignore, I mean. Don't think, 'I haven't lived, but she did'; I don't think like that, I mean. My eyes filled with tears many times, I mean." (Turkey, male, 46)
} 
In addition to strong expressions of empathy regarding those affected by earthquakes, a cluster of moral emotions was strongly present in the Turkish data while nearly absent in the U.S. and Japanese data. It concerned the corruption and incompetence of political and economic elites (notably politicians, civil servants, planning regulators, and the construction industry). Discussion of corruption in the Turkish data was often accompanied by expressions indicating lowered collective self-esteem. Two thirds of Turkish participants expressed a demise of identity, describing Turkish society as immoral or incompetent. This was strongly associated with perceptions of corrupt Turkish elites:

"Our politicians should spot what the real needs of the people are, find out how to get the least share from the pain, instead of making and selling pasteurized eggs out of rotten ones, and making pretty pennies out of dead donkeys." (Turkey, female, 56)

This demise of identity influenced people's representations of risk because corruption, greed, and selfishness were seen to produce vulnerable cities and buildings. Just under half of participants directed blame for this corruption toward government and state institutions, and a similar number toward economic and business elites:

"Today people make so much effort to have a family. And I may also lose my family [during an earthquake] because of the fraud and irresponsibility of the ones in power. But how do they sleep at night with a comfortable conscience? What kind of a conscience do they have?" (Turkey, female, 29)

Less prevalent but still apparent emotions included feelings of distrust and anger. These two emotions tended to be expressed more by younger Turkish participants (those aged between 20-49) than by the older people (50-79) in the sample. Distrust was frequently coupled with assessments of the vulnerability of the built environment, and so indirectly with aspersions of corruption and poor construction practices:

\footnotetext{
"Everyone is worried, but they are living even in the buildings that they know not to be solid; they continue living in them, because there is no other solution. What is presented as a solution to them is just utter nonsense. I call it nonsense, especially nonsense. An earthquake happened in Erzurum. The so-called earthquake housing constructed there was far from fully meeting the needs of the people living in there. How their locations were selected, that is also doubtful." (Turkey, female, 56)
}

Anger, too, was associated with the poor state of the built environment and was directed at the construction industry and the state that regulates and monitors it:

"In that earthquake I mentioned, a building near Tansas cracked all the way from top to bottom. And they plastered and painted it up instead of repairing that. I mean, for the people to come, for the ones who want to buy a house. I witnessed that; I got so upset then. Right in front of your eyes, the building had cracked into two for good." (Turkey, female, 36)

As in the Japanese and U.S. data, Turkish respondents often compared their home with other places. However, while the frequency with which respondents compared Turkey to other places was not quantitatively dissimilar from either the Japanese or U.S. data, the content and psychological consequences of the Turkish comparisons were very distinctive. While Japanese and U.S. respondents used place comparisons as a means of positioning their homes as safe relative to other places, Turkish people used them to point to their heightened risk relative to other places. There were frequent mentions of Japan as a 
country where earthquake protection was well-organized, in addition to comparisons with western Europe:

"Why is this country going like this? Why? We are in a country, which is always exploited, always used, so vulgarly, like a checker piece at people's fingertips. I've also seen Europe. Although we were foreigners and lower than their own people, in their eyes of course, they still lived much perfectly compared to here, to my own country; but coming here, in the health sense, in the security sense, in every sense it is so average, so insufficient." (Turkey, female, 57)

In sum, the Turkish participants' emotional associations differed considerably from those of the Japanese and U.S. participants. While fears, worries, and anxieties were prominent in all groups, the Turkish interviewees were more consumed by grief, pain and sadness than either the Japanese or U.S. respondents. Perhaps the most striking difference was the strong sense of demise of identity on a national scale, with responses to earthquake risk permeated by the widespread belief that the character and moral fiber of the country was weak and corrupt. This was reinforced by the many comparisons of Turkish with Western and Japanese ways of dealing with earthquakes. Whereas the Turkish saw their own elites and national character as selfish, immoral, ignorant, corrupt, and degraded, other nations and their peoples were seen as enlightened, efficient, honorable, and upright. Attendant to these comparisons were strong expressions of anger, blame, and distrust.

\section{Discussion of Theme 1}

There were fundamental similarities between the three groups of participants regarding their emotional and moral responses to earthquakes. The dominant reaction was one spanning the spectrum from worry through to anxiety and fear, with earthquakes represented as a potent threat to the basic security and built environment of people living in the three areas. However, a surprising number of U.S. participants seemed to have a more positive emotional response to earthquakes, seeing them as awe-inspiring spectacles that might come from a Hollywood movie. This stood in stark contrast to the outpouring of pain and sadness evident in the Turkish, and, to a lesser extent, in the Japanese narratives. This might be partly connected to experience, in that at a national level, the Turks and Japanese had experienced more recent major earthquake-related losses than the North Americans had.

Alongside these emotions, U.S. and Japanese participants also moved to distance themselves symbolically from earthquake threats. This was particularly evident in the U.S. participants, who compared other places unfavorably with their home domain. Whether it was California, Louisiana (particularly in relation to Hurricane Katrina), or unnamed Asian countries, home was safer than these places. This trend was further evident in some of the Japanese responses, which also placed threat outside of their home region. However, the Turkish reaction was sharply different - they compared other places and countries to their own and found their own country and city deficient in both material and symbolic terms. This was connected to a deep sense of corruption attributed to Turkish elites. The results corroborate Green's (2008) finding that Turkish participants typically saw political and economic elites as corrupt and untrustworthy. Inasmuch as elites were largely seen as responsible for designing, building and regulating Turkish built environments, failing cities mirrored a failing national character, creating a vicious cycle of increasing vulnerability. Turkish interviewees were torn between a strong sense of 
solidarity and group worth, as evident in the empathy, pain and anguish expressed at their collective losses, and a sense that their country and national character was fundamentally flawed.

Levels of seismic adjustment reported for each country in the questionnaire corresponded with the strength of negative emotions identified in the qualitative analysis. The U.S. participants, who reported the highest levels of seismic adjustment behavior, seemed to have a somewhat attenuated level of negative emotional response relative to the other countries, and indeed were unique in their expression of positive emotional associations with earthquakes. Meanwhile, the lowest adjustment rates occurred in Turkey, where strong negative emotions were linked to distrust in government and building professionals. Thus, uncovering the emotional dynamics of cultural responses to earthquakes enhances understanding of why people who live in areas of high seismic risk do not act to reduce their risk: mediating emotional variables, such as anxiety, spoiled identity, and distrust, may function as barriers to action.

\section{Theme 2: Agency and Control in Relation to Earthquakes}

A considerable proportion of the interviews in all three sites involved talk about agency, efficacy, and control regarding earthquakes and earthquake risk reduction. As Figure 4 shows, a majority of participants demonstrated that they were aware of seismic adjustment measures, spontaneously mentioning actions they could take to protect themselves from earthquakes or mitigate damage. However, for many participants in all three sites, this awareness competed with a sense of fatalism concerning earthquake risk. This was especially marked in Turkey, with nearly all participants referring to fatalistic beliefs held by themselves or others in their surroundings. Many of the Turkish interviewees represented earthquakes as "acts of God," causally implicating divine providence in their occurrence. U.S. and Japanese participants oriented more toward the causal frame of earthquakes as "acts of nature." The

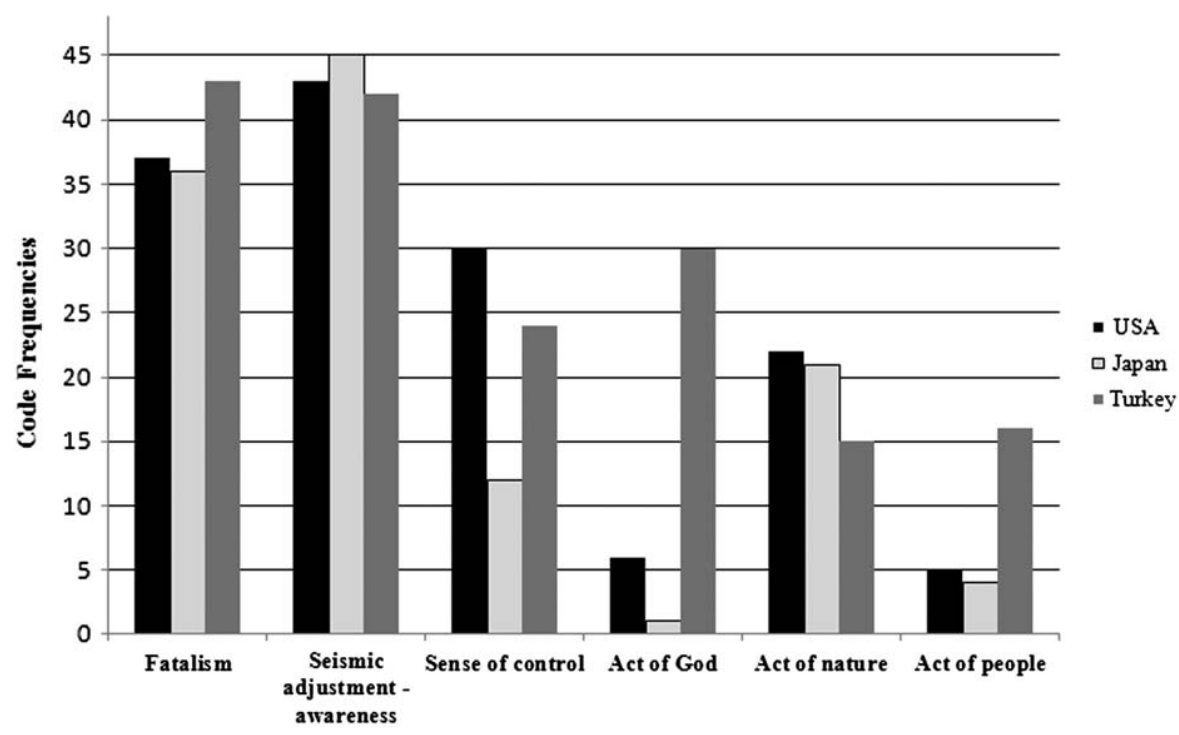

Figure 4. Frequency of agency and control codes by country. 
following section outlines the texture of each country's representations of agency and control regarding earthquakes.

\section{U.S. Responses}

Talk of control, agency, and fate was prominent in U.S. representations of earthquakes. Participants frequently expressed a belief that they or others are largely helpless in the face of earthquakes, signifying a degree of fatalism:

"If an earthquake is going to occur, there's nothing I can do about it, so it's out of my control." (United States, male, 40)

In the U.S. data, fatalism was strongly associated with the representation of earthquakes as acts of nature, phenomena that are outside the domain of human intervention:

"So there's really no defense. You can't build something sturdy enough to mess with Mother Nature; we're just little human specks on this Earth, and Mother Nature is a lot more serious than we are, and we're kind of kidding ourselves if we think we can build stuff to completely survive in the worst-case event." (United States, male, 61)

Perceived helplessness regarding earthquakes, however, was not absolute. While respondents frequently pointed to the uncontrollability of the occurrence and nature of earthquakes, many indicated that humans could mitigate their effects and most $(90 \%$ of U.S. participants) demonstrated awareness of seismic adjustment actions that might protect life and property:

"I think I have absolutely no control about when an earthquake is happening. I think I have control as to my reaction to an earthquake in terms of my preparation, my follow-through, my knowledge of what to do, but in terms of having any sort of insight as to when they're coming, how they're coming, no, I don't think so. I can, I can watch and learn as much as I can, I can listen to others who are professionals, take that into consideration, but that's about it." (United States, female, 34)

Thus, in the U.S. data, a general sense of earthquakes as uncontrollable acts of nature co-existed with knowledge that measures can be adopted to help insulate oneself against earthquake risk.

\section{Japanese Responses}

As in the U.S. sample, a strong majority of Japanese participants expressed a lack of control or sense of unavoidable destiny about the occurrence and consequences of earthquakes:

"This is unpreventable; it occurs suddenly. I certainly think that it is inescapable. It is difficult to escape and difficult to prevent by myself." (Japan, female, 39)

Such fatalism regarding one's own capabilities extended to collective efforts at preparing for and mitigating earthquake disasters:

"The government is trying to predict an earthquake, but I think it is impossible, although the government is doing so. And we cannot defeat nature." (Japan, female, 70)

Across the three countries, the Japanese data contained the lowest prevalence of expressions of control. Older Japanese participants were especially unlikely to express a sense of control over earthquakes, with only two Japanese people aged over 50 asserting that some control was 
possible. This lack of control was often rooted in a framing of earthquakes as acts of nature, removed from the sphere of human influence. This view of earthquakes represented the movements of the earth as external, autonomous forces over which humans are powerless:

"The movement of the earth's crust cannot be prevented by humans; it is impossible. The natural calamities as well; I've got the impression that nothing can be done, it is different from crimes and war." (Japan, male, 44)

However, as in the U.S. data, alongside these representations of helpless individuals and communities was widespread acknowledgement of potential seismic adjustment measures, with $94 \%$ of Japanese participants mentioning measures that could mitigate earthquake threats and aid post-event survival. Thus, fatalism and helplessness were accompanied by awareness that action could be taken to reduce damage:

\begin{abstract}
"Construct housing with non-collapsing techniques or arrange city planning to prevent the spread of fire. By doing so, we can reduce the extent of the damage after the disaster happens. I think that we can also apply the same measures against tsunami. On the contrary, we can prevent crimes and wars in advance, but there is a big difference compared to the typhoons, tsunami, and earthquakes; these are inevitable. That is why I said that nothing can be done, but we can do something about it, although we cannot stop it from happening." (Japan, male, 44)
\end{abstract}

Thus, Japanese representations of earthquakes as unconquerable forces of nature gave rise to fatalism and expressions of helplessness, but these were diluted somewhat by awareness of behavioral options that reduce the risks posed by earthquakes.

\title{
Turkish Responses
}

As in the U.S. and Japanese interviews, a sense of fatalism and helplessness was pervasive among the Turkish participants, with the vast majority expressing such beliefs. Similarly to the other two samples, fatalism was expressed both in relation to self and the wider community:

"Okay, you can construct the building solidly, but what if the ground of the building where you live cracks? Wouldn't it take that building inside if it effervesces? I think it would. I accept nothing as a precaution, nothing! If you like, you have a cage made of gold, iron, or steel. When the earthquake comes and hits, all are gone." (Turkey, female, 57)

"I am not so hopeful. I mean, how shall I say: There is no state policy or sensitivity of the people to attract me. As I've just said, the people in Istanbul know that the building will collapse, but they have to live in there as well. There is not much those people can do. I mean, the state or the local governments have to support them. They have to direct those people in some way. Or else, what can you do individually? If you don't have a financial power, what can you do? " (Turkey, male, 29)

As can be seen from these excerpts, Turkish fatalism resulted from a complex set of interrelated beliefs about lack of efficacy and control at the individual, group, and community levels. Fatalism was also a matter of degree; the former quote displayed a view of humans as inevitably and fundamentally overpowered by earthquakes, while the latter illustrated a type of fatalism grounded in the idea that levels of control are contingent on resource availability and political support, which were not currently forthcoming. This latter type of fatalism was common in the Turkish data, with people perceiving institutional and structural failings of a scale that almost guaranteed major disaster in a seismic event. 
Over half of the Turkish interviewees referred to beliefs that earthquakes come from God (or Allah), a much greater proportion than their U.S. and Japanese counterparts. Such beliefs were a significant contributor to fatalism and helplessness in many respondents:

"Desperation. There is nothing we can do. We say it came from Allah." (Turkey, male, 61)

Attributing earthquakes to the divine or supernatural did not, however, inevitably undermine human agency. Religious beliefs enhanced feelings of personal control for some people, as they felt that they could help or protect themselves by praying. Ideas about fate and destiny were sometimes woven together with ideas of human agency and control:

"Of course, we don't know what will happen and when. Neither you nor I can create the earthquake when we want. This is also a law of nature. This is what Allah has written for us; it is going to happen, but we don't know when it will happen. We know that we have to be prepared and ready all the time." (Turkey, female, 57)

Alongside representations of fatalism and helplessness, $88 \%$ of Turkish participants mentioned adjustments that could be adopted. Indeed, half of the sample expressed that they had some sense of control in relation to earthquakes:

"The earthquake is also something in the hands of the people along with being a natural disaster. I mean, the earthquake might happen, but if the people take some precautions, and if they are aware and trained, I mean, they can get off such a disaster with much less things. At the end, I mean, one shouldn't see earthquake as such a fearsome, big disaster. One needs to get used to this at some point and live with this, taking precautions." (Turkey, female, 52)

In summary, Turkish ideas and beliefs about fate, control and agency were complex and multilayered. Attributing earthquake occurrences to divine will was common, and a strong streak of fatalism pervaded participants' accounts. This was countered by acknowledgement that there were various means of preparing for and mitigating earthquake damage.

\section{Discussion of Theme 2}

Participants in all three sites shared a representation of themselves and their communities as partially helpless in the face of earthquakes, but these ideas were presented within different causal frames. U.S. and Japanese participants tended to see earthquakes and their consequences as acts of nature whose unpredictable force and scope make their occurrence unavoidable and uncontrollable. While Turkish participants also tended toward fatalism, their representations of the causal nature of earthquakes were more mixed. Turkish representations contained a much stronger focus on vulnerabilities caused by institutional and collective failings, implying a view of earthquakes' consequences as largely determined by the actions of people and society. The Turkish data also displayed an important religious dimension in orientations toward earthquake risk, seeing earthquakes as divine provenance. Turkish causal representations of earthquakes were therefore complex: on the one hand, earthquake disasters were blamed firmly on the actions of individuals and groups; on the other, divine will was invoked as an unavoidable force.

All three sets of data showed high levels of awareness that behavioral options existed by which people could reduce their earthquake risk. This sits somewhat uneasily with the strong 
trends toward fatalism: How could people simultaneously assert that earthquakes are something over which they can exert no control, and demonstrate knowledge of steps that can be taken that would help protect against earthquake threat? There are numerous possibilities for how this contradiction could be maintained in people's minds. Firstly, it is possible that people did not believe that adjustment activities would have much effect in the event of a major earthquake; therefore, knowing about adjustment activities did not lend itself to a sense of control, nor to a high seismic adoption rate. Alternatively, people may have been conscious of material constraints on their ability to adopt adjustments. For example, financial constraints may prevent someone from purchasing earthquake insurance, people may not have had the opportunity to learn first aid, or (as was noted earlier) renting one's residence and living in an apartment rather than a house may undermine people's ability to make structural changes to their residence. Such material inhibitions should be taken into consideration, though their explanatory value is incomplete, as there are many potential adjustments - such as safely arranging furniture, storing water, and having an emergency plan - that are unlikely to be directly affected by such material constraints. Finally, it is possible that the apparently contradictory elements (fatalism and awareness of adjustment options) operate on two different levels of the psychological system: Participants might have known rationally that there were steps that they could take to increase their safety in a future earthquake, but this was overwhelmed by an emotional response to threat that dictated that no control is possible and that action is futile.

In terms of actual adjustment behavior, it is clear that the high levels of awareness did not translate into high adjustment activity. The quantitative data indicated relatively low levels of adoption of seismic adjustments, especially in Japan and Turkey. It is possible that fatalism and a low sense of control functioned as barriers for the translation of awareness into concrete action.

\section{CONCLUSIONS}

\section{HOW DO PEOPLE IN SEATTLE, IZMIR, AND OSAKA SEE THEIR EARTHQUAKE RISK?}

Lay people in each city were clearly aware that they were under threat from earthquakes, with the Japanese ranking earthquakes as their most threatening hazard. The Turkish and Japanese had strongly negative emotional associations with earthquakes, primarily relating to fear and anxiety, and - particularly for the Turkish group — grief and pain. U.S. participants also displayed these negative emotional associations, but in a more muted form, moderated by exhilaration and awe.

Participants in all research sites spontaneously evaluated their risk with reference to the risk faced by other places. While Seattle and Osaka residents saw their own area as less vulnerable to earthquakes than the places to which they compared themselves, the Izmir respondents felt that other countries were safer than Turkey, with their risk perceived to be heightened due to an untrustworthy government and corrupt construction industry. People's beliefs about their society and collective identity fed their representations of earthquake risk; the spoiled identity of Turkish respondents led them to feel that their risk was inflated relative to other places, while the place comparisons made by American and Japanese 
participants cultivated a sense of enhanced security, safety, and indeed, superiority, relative to other countries.

While people in all three cities were aware of the seismic potential of their area, statements indicating that they were unlikely to be harmed were common, particularly in the U.S. group. Such sentiments might be explained with reference to the concept of optimistic bias, a core idea in the psychology of risk that refers to people's tendency to see themselves as less likely to be harmed by future dangers than similar others. The U.S. respondents demonstrated the greatest tendency toward optimism and regularly stated that they were not afraid of earthquakes. Such statements were rare in the Turkish sample, and while the Japanese sometimes disclaimed their vulnerability to earthquakes, proclamations that they were vulnerable were more frequent and accompanied by intense anxiety and fear. This is consistent with Palm and Carroll's (1998) finding that optimistic bias regarding earthquakes was more common within American than Japanese communities. Palm and Carroll (1998) attributed this difference to the effects of cultural trends toward individualism (which may support an evaluation of the self as better off than others) in the United States and collectivism in Japan. It could also, however, reflect differences in seismic experience (Helweg-Larsen 1999), with Turkish and Japanese potentials for optimism undermined by their experience of damaging, high-fatality earthquakes in their recent past. Support for this is found in the prominence of the "reality shift" code in the Japanese data; many Japanese participants related that after the Kobe earthquake it was more difficult to maintain an image of themselves as protected (perhaps by the country's advanced technology) from earthquake loss and damage. Interestingly, however, in light of the subsequent 2011 Tohoku-oki earthquake and tsunami, only a handful of Japanese participants mentioned the threat posed by tsunami and, when they did, this was most often with reference to the 2004 Indian Ocean tsunami.

The interplay of feelings and beliefs that permeated people's sense of their earthquake risk was thus nuanced and complex, producing representations that were culturally variable and emotionally loaded. It is unlikely that this complexity would have manifested if participants had been restricted to predefined response options in a questionnaire. The qualitative interview-based design produced a rich and detailed set of data on a matched cross-cultural sample, furnishing insight into the content and form of people's naturalistic thinking regarding earthquake hazards.

\section{DO THEY PREPARE FOR A POTENTIAL EARTHQUAKE?}

Consistent with existing literature on the adjustment behavior of people in seismically hazardous areas, little to very little preparation was undertaken. Overall the number of seismic adjustments undertaken in all cities was low, though Seattle levels ranked significantly higher than Izmir and Osaka. The preferred types of seismic adjustment were low-cost measures that would increase survival chances after the earthquake and that were relevant to multiple types of hazards. The main measures adopted related to information, such as knowing designated evacuation sites and how to turn off the gas, and ensuring the availability of emergency food, water, medicines, and communication devices. Structural retrofitting was undertaken by no Turkish and only seven American and eight Japanese participants. This is particularly worrying given that the data collected on participants' housing indicated that it was not built to current seismic standards. It should be noted that ability to undertake such 
structural measures is likely to be affected by material factors, such as whether people own or rent their residence; all those who reported retrofitting were owners of their home.

\section{WHAT IS THE LINK BETWEEN HOW THEY SEE THEIR RISK AND HOW THEY PREPARE FOR A POTENTIAL EARTHQUAKE?}

The data demonstrated that substantial awareness of both earthquake risk and potential adjustment measures in all sites did not translate into mitigative action. Intense levels of fear and anxiety about earthquakes seem to be implicated in the low seismic adjustment in Japan and Turkey. This is consistent with the questionnaire data that suggested that feeling more secure in one's house (as homeowners and house-dwellers did in the U.S. sample) was linked to higher levels of adjustments. The causal direction of this relationship is difficult to establish. It is possible that Japanese and Turkish participants felt anxious because they were aware they had not taken sufficient adjustment action. Alternatively, it is possible that the direction of causality runs the other way, that high levels of anxiety undermined adjustment action. A more moderate level of anxiety, as displayed by the U.S. participants, may be more facilitative of adjustment behavior. This runs counter to the assumption that the more threatening a person perceives their risk to be, the more likely they are to take action. It is interesting that in the current study, the Turkish group, who felt most vulnerable and used place comparisons to emphasize their elevated risk of earthquakes, displayed the lowest adoption of adjustment measures. The link between low adjustment and high anxiety may indicate that interventions that seek to promote adjustment by increasing people's perceptions of seismic risk are misguided.

This pattern is difficult to reconcile with a rationalistic conceptual frame that assumes that adjustment behavior will result from people perceiving that they are at high risk. However, it is comprehensible when the emotional and sociocultural dimensions of the link between risk perception and behavior are considered. Participants' perceptions of themselves as being at high risk stimulated fear and anxiety, particularly intensely in the Turkish and Japanese samples. It is possible that rather than motivating protective behavior, these emotions may have overwhelmed and paralyzed people, preventing them from action. Action seemed to be further inhibited by cultural trends toward fatalism; cultural framing of earthquakes as caused by the insurmountable power of nature or by divine will left participants feeling helpless, with belief in the efficacy of their risk-reducing efforts (on both a personal/household and community/state levels) extremely low, particularly in the Turkish sample.

The sense of collective efficacy in the ability to mitigate the effects of earthquakes may also have been undermined by low levels of societal trust, which were particularly striking in the Turkish interviews. This corroborates the findings of Green (2008), which implicated distrust of the Turkish construction industry, engineers, and regulatory bodies in the reliance of Istanbul residents on vernacular construction practices that differed from officially sanctioned best practice. In the current study, Turkish representations of the political, regulatory, and construction spheres as corrupt and incompetent gave rise to feelings of distrust, anger, and blame, and fed a sense of degraded national identity.

A further possible explanation for why seismic adjustment is higher in the United States is provided by past research that suggests that adjustment is enhanced in individualistic cultures, which attribute responsibility to self, and undermined in collectivist cultures that 
emphasize the role of state and community in mitigating disasters (Palm and Carroll 1998). Perceived personal responsibility may therefore be a factor that has stimulated the U.S. respondents to take seismic adjustment actions. Ascriptions of responsibility did not occur spontaneously in the majority of the interviews, and the study is therefore limited in the extent to which it can address the link between responsibility beliefs and adjustment behavior. The Turkish participants did talk about government action, such as stronger regulation, monitoring and censuring of corruption and poor construction practices. However, such actions were more often presented as ideals that might never come to fruition, rather than realistic governmental responsibilities. The suggestion that Izmir's low behavioral adjustment resulted from their delegation of protection responsibility to the state and collective is therefore uncertain.

It is worth noting that the scale used to measure adjustment behaviors focuses almost exclusively on measures undertaken by individuals or households. It does not investigate more collective activities, such as advocating for improvements in building codes or attending community meetings. The indicator of adjustment may therefore be culturally biased, not tapping the collective efforts to prepare for earthquakes, in which respondents may have participated. Further research should aim to develop an index of adjustment behavior that is more sensitive to how earthquake mitigation/protection measures might manifest differently across different cultural contexts.

\section{IMPLICATIONS FOR DISASTER RISK REDUCTION INITIATIVES}

This study suggests that heightened risk perception and awareness of seismic adjustment measures are unlikely to promote the uptake of seismic adjustment measures. Therefore, risk awareness-raising campaigns alone are of limited use in promoting citizen-led mitigative actions. If they evoke anxiety, the data in this study suggest that they may be counterproductive, fuelling a sense of paralysis in the face of the forces of nature or God. Rather than stimulating fear, risk reduction initiatives need to elicit feelings of collective- and self-efficacy among people in highly seismic regions. Various ways of achieving this are proposed.

Firstly, the effectiveness of risk reduction campaigns may be enhanced by focusing on the more comforting, rather than anxiety-provoking, aspects of preparing oneself for the range of dangers on the horizon. Imparting the sense that there are a range of steps that "I can" and "we can" take to mitigate disasters may function to counterbalance the fatalism associated with earthquakes. As anxiety-provoking messages often evoke the denial that is at the root of distancing the danger from the self in space and time, more comforting messages might support an understanding of earthquakes as "here-and-now" dangers. Furthermore, since earthquakes have such long return periods, it may be easier to convince people to take measures that prepare them for an array of related dangers, some of which have shorter return periodsfor example, learning to administer first aid or developing a plan for communicating with others in emergencies would apply to such disasters as floods and fires, as well as to earthquakes.

Secondly, the need to promote collective efficacy, in particular, also implies the use of participatory and community-based approaches to disaster risk reduction, rather than passive campaigns, such as general publicity and leaflets. Such community-based initiatives should aim to elicit action not just by instilling the intention to implement preparatory behaviors, but 
by directly facilitating the preparatory behavior itself. This may range from such measures as providing access to retrofitting services, to teaching people where their gas is and how to shut it off, to preparation of the emergency kits necessary for a range of dangers.

Thirdly, this study highlights strong cultural differences between the sites investigated, which reinforces the importance of developing culture-specific disaster mitigation plans. These should look beyond the usual issues associated with differences in building design, construction practice, building code enforcement, and financial resources, to tackle people's levels of trust. The striking lack of trust in government and the construction industry in Izmir is likely to impede the effective implementation of any mitigation plan led or promoted by government. To improve efficacy, disaster risk reduction initiatives should be led and promoted by those who are trusted in a particular cultural context.

Changes in perceived personal risk, trust, and control cannot be achieved in a short time frame, as they are deeply embedded within the social representations that circulate in a given culture. However, identification of the barriers to seismic adjustment via empirical research forms the first step in challenging and gradually changing them.

\section{ACKNOWLEDGEMENTS}

This work was funded by the Engineering and Physical Sciences Research Council (Grant ref. EP/F012179/1). We are very grateful to Professor Nuray Karançi and Berat Yoldas of Middle East Technical University, Turkey, and Professor Katsuya Yamori and Dr. Mayumi Sakamoto of Kyoto University, Japan, for their help with the Turkish and Japanese interviews and to the three anonymous reviewers for their useful comments.

\section{REFERENCES}

Akinci, A., Eyidoğan, H., Göktürkler, G., Akyol, N., and Ankaya, O., 2000. Investigation of the seismic activity and seismic hazard of Izmir City and its vicinity, Earthquake Risk Assessment of West Anatolian Symposium, 231 pp.

Arlikatti, S., Lindell, M. K., and Prater, C. S., 2007. Perceived stakeholder role relationships and adoption of seismic hazard adjustments, International Journal of Mass Emergencies and Disasters 25, 218-256.

ATLAS.ti, 2011. User Manual for ATLAS.ti 6.0, ATLAS.ti Scientific Software Development, Berlin.

Bandura, A., 1977. Self-efficacy: Toward a unifying theory of behavioral change, Psychological Review 84, 191-215.

Blakely, R. J., Wells, R. E., Weaver, C. S., and Johnson, S. Y., 2002. Location, structure, and seismicity of the Seattle fault zone, Washington: Evidence from aeromagnetic anomalies, geologic mapping, and seismic-reflection data, Geological Society of America Bulletin 114, 169-177.

Boyatzis, R. E., 1998. Transforming Qualitative Information: Thematic Analysis and Code Development, Sage Publications, Thousand Oaks, CA, 200 pp.

Brewer, M. B., and Chen, Y. R., 2007. Where (who) are collectives in collectivism? Toward conceptual clarification of individualism and collectivism, Psychological Review 114, $133-151$. 
Earthquake Engineering Field Investigation Team (EEFIT), 1997. The Hyogo-Ken Nanbu (Kobe) Earthquake of 17 January 1995: A Field Report by EEFIT, available at http://www.istructe .org/knowledge/EEFIT/Documents/Kobe.pdf (last accessed 3 October 2011).

Earthquake Engineering Research Institute (EERI), 2001. The Nisqually Earthquake of $28^{\text {th }}$ February 2001: Preliminary Reconnaissance Report, available at http://www.eeri.org/lfe/ pdf/usa_nisqually_preliminary_report.pdf (last accessed 3 October 2011).

Giardini, D., Grünthal, G., Shedlock, K.M., and Zhang, P., 2003. The GSHAP Global Seismic Hazard Map, in International Handbook of Earthquake \& Engineering Seismology, International Geophysics Series 81 B, W. Lee, H. Kanamori, P. Jennings and C. Kisslinger (editors), Academic Press, Amsterdam, 1233-1239.

Gjerde, P., and Onishi, M., 2000. Selves, cultures and nations: The psychological imagination of 'the Japanese' in the era of globalization, Human Development 43, 216-226.

Green, R., 2008. Unauthorised development and seismic hazard vulnerability: A study of squatters and engineers in Istanbul, Turkey, Disasters 32, 358-376.

Helweg-Larsen, M., 1999. (The lack of) optimistic bias in response to the 1994 Northridge earthquake: The role of personal experience, Basic and Applied Social Psychology 21, 119-129.

IBM SPSS, 2011. IBM SPSS Statistics, available at http://www-01.ibm.com/software/analytics/ spss/products/statistics/ (last accessed 2 September 2011).

Irikura, K., 2000. Prediction of strong motions from future earthquakes caused by active faults case of the Osaka basin, in Proceedings, Twelfth World Conference on Earthquake Engineering, paper 2687, Auckland, 1243-1250.

Hofstede, G., 1983. The cultural relativity of organizational practices and theories, Journal of International Business Studies 14, 75-89.

Hollway, W., and Jefferson, T., 1997. Eliciting narrative through the in-depth interview, Qualitative Inquiry 3, 53-70.

Jackson, E. L., 1981. Response to earthquake hazard: The west coast of North America, Environment and Behavior 13, 387-416.

Joffe, H., 2003. Risk: From perception to social representation, British Journal of Social Psychology 42, 55-73.

Joffe, H., 2011. Thematic analysis, in Qualitative Research Methods in Mental Health and Psychotherapy: A Guide for Students and Practitioners, D. Harper and A. Thompson (editors), John Wiley \& Sons, Chichester, UK, 209-223.

Joffe, H., and O'Connor, C., 2013. Risk society and representations of risks: Earthquakes and beyond, in Cities at Risk: Living with Perils in the $21^{\text {st }}$ Century, H. Joffe, T. Rossetto and J. Adams (editors), Springer, Dordrecht, The Netherlands, 9-23.

Johnson, S. Y., Dadisman, S. V., Childs, J. R., and Stanley, W. D., 1999. Active tectonics of the Seattle fault and central Puget Sound, Washington: Implications for earthquake hazards, Geological Society of America Bulletin 111, 1042-1053.

Kanaori, Y., and Kawakami, S., 1996. The 19957.2 magnitude Kobe earthquake and the Arima-Takatsuki tectonic line: Implications of the seismic risk for central Japan, Engineering Geology 43, 135-150.

Kirschenbaum, A., 2005. Preparing for the inevitable: Environmental risk perceptions and disaster preparedness, International Journal of Mass Emergencies and Disasters 23, 97-127.

Lindell, M. K., 2013. North American cities at risk: Household responses to environmental hazards, in Cities at Risk: Living with Perils in the $21^{\text {st }}$ Century, H. Joffe, T. Rossetto and J. Adams (editors), Springer, Dordrecht, The Netherlands, 109-130. 
Lindell, M. K., and Perry, R. W., 2000. Household adjustment to earthquake hazard: A review of the research, Environment and Behavior 32, 461-501.

McClure, J., Allen, M., and Walkey, F. H., 2001. Countering fatalism: Causal information in news reports affects judgments about earthquake damage, Basic \& Applied Social Psychology 23, 109-121.

McClure, J., Sutton, R. M., and Wilson, M., 2007. How information about building design influences causal attribution for earthquake damage, Asian Journal of Social Psychology 10, 233-242.

Mileti, D. S., and Fitzpatrick, C., 1992. The Great Earthquake Experiment: Risk Communication and Public Action, Westview Press, Boulder, CO, 149 pp.

Moscovici, S., 1988. Notes towards a description of social representations, European Journal of Social Psychology 18, 211-250.

Moscovici, S., 2008. Psychoanalysis: Its Image and Its Public, Polity Press, Cambridge, 416 pp.

Mulilis, J.-P., and Lippa, R., 1990. Behavioral change in earthquake preparedness due to negative threat appeals: A test of Protection Motivation Theory, Journal of Applied Social Psychology 20, 619-638.

National Oceanic and Atmospheric Administration (NOAA), 2011. The Significant Earthquakes Database, available at http://www.ngdc.noaa.gov/nndc/struts/form?t=101650\&s $=1 \& \mathrm{~d}=1$ (last accessed 2 September 2011).

Palm, R., 1998. Urban earthquake hazards: The impacts of culture on perceived risk and response in the US and Japan, Applied Geography 18, 35-46.

Palm, R., and Carroll, J., 1998. Illusions of Safety: Culture and Earthquake Hazard Response in California and Japan, Westview Press, Boulder, CO, 136 pp.

Paton, D., Bajek, R., Okada, N., and McIvor, D., 2010. Predicting community earthquake preparedness: A cross-cultural comparison of Japan and New Zealand, Natural Hazards 54, 765-781.

Rossetto, T., Joffe, H., and Solberg, C., 2011. A different view on human vulnerability to earthquakes: lessons from risk perception studies, in Human Casualties in Earthquakes: Progress in Modeling and Mitigation, R. J. Spence, E. So and C. Scawthorn (editors), vol. 29, Springer, Dordrecht, The Netherlands, 291-304.

P. Slovic (editor), 2010. The Feeling of Risk: New Perspectives on Risk Perception, Earthscan, London, $456 \mathrm{pp}$.

Solberg, C., Rossetto, T., and Joffe, H., 2010. The social psychology of seismic adjustment, Natural Hazards and Earth System Sciences 10, 1663-1677.

Spittal, M. J., McClure, J. L., Siegert, R. J., and Walkey, F. H., 2008. Predictors of two types of earthquake preparation: Survival activities and mitigation activities, Environment and Behavior 40, 798-817.

Spittal, M. J., Walkey, F. H., McClure, J. L., Siegert, R. J., and Ballantyne, K. E., 2006. The earthquake readiness scale: The development of a valid and reliable unifactorial measure, Natural Hazards 39, 15-29.

Tierney, K. J., Lindell, M. K., and Perry, R. W., 2001. Facing the Unexpected: Disaster Preparedness and Response in the United States, Joseph Henry Press, Washington, D.C., 320 pp.

Turner, R., Nigg, J., and Heller Paz, D., 1986. Waiting for Disaster, University of California Press, Los Angeles, CA, 426 pp. 
United States Geological Survey (USGS), 2009. Washington: Earthquake History, available at http://earthquake.usgs.gov/earthquakes/states/washington/history.php (last accessed 3 October 2011).

B. Wisner and J. Adams (editors), 2002. Environmental Health in Emergencies and Disasters: A Practical Guide, World Health Organization, Geneva, 280 pp.

Yamaguchi, D. K., Atwater, B. F., Bunker, D. E., Benson, B. E., and Reid, M. S., 1997. Tree-ring dating the 1700 Cascadia earthquake, Nature 389, 922-923.

(Received 5 October 2011; accepted 17 October 2012) 